\title{
Norwegian testing of the EURANOS framework for post-accident rehabilitation preparedness
}

\author{
A. LILAND ${ }^{1}$, D. OUGHTON ${ }^{2}$, I. BAY-LARSEN ${ }^{3}$, I.M. EIKELMANN ${ }^{1}$, \\ H.S. HANSEN ${ }^{1,4}$, L. SKUTERUD ${ }^{1,5}$
}

\begin{abstract}
Based on the framework for post-accident rehabilitation preparedness elaborated in the EURANOS project (Dubreuil et al., 2010), a Norwegian Pilot Study was conducted in spring 2008 to test the suggested method. This article describes the method used in the Norwegian Pilot Study and the outcomes of the co-expertise meetings arranged.
\end{abstract}

\section{Background}

The radioactive fallout over Norway after the Chernobyl accident was substantial. Even today, 24 years later, countermeasures are necessary in agriculture and reindeer husbandry to produce milk and meat that comply with the Norwegian food intervention levels (Liland et al., 2009).

In 1986, there were no existing plans for post-accident long-term rehabilitation of contaminated areas. A management system was initiated during spring and summer 1986, and further developed the following years. The solutions were developed as a cooperation between national and regional regulators and in dialogue with local farmers and reindeer herders in some areas. The focus was on measures in the food production chain, like clean feeding, distribution of Prussian blue, live monitoring of animals and dietary advice for vulnerable groups. Less attention was given to other aspects such as health issues, information needs and local challenges in the most contaminated areas.

\footnotetext{
1 Norwegian Radiation Protection Authority, Department for Emergency Preparedness and Environmental Radioactivity, PO Box 55, 1332 Østerås, Norway.

2 Norwegian University of Life Sciences, Department of Plant and Environmental Sciences, PO Box 5003, 1432 Ås, Norway.

3 Nordland Research Institute, Department for Entrepreneurship, Innovation and Regional Development, Mørkvedtråkket 30, 8049 Bodø, Norway.

4 Nord-Trøndelag University College, Serviceboks 2501, 7729 Steinkjer, Norway.

5 Norwegian Reindeer Husbandry Authority, PO Box 121, 7361 Røros, Norway.
} 


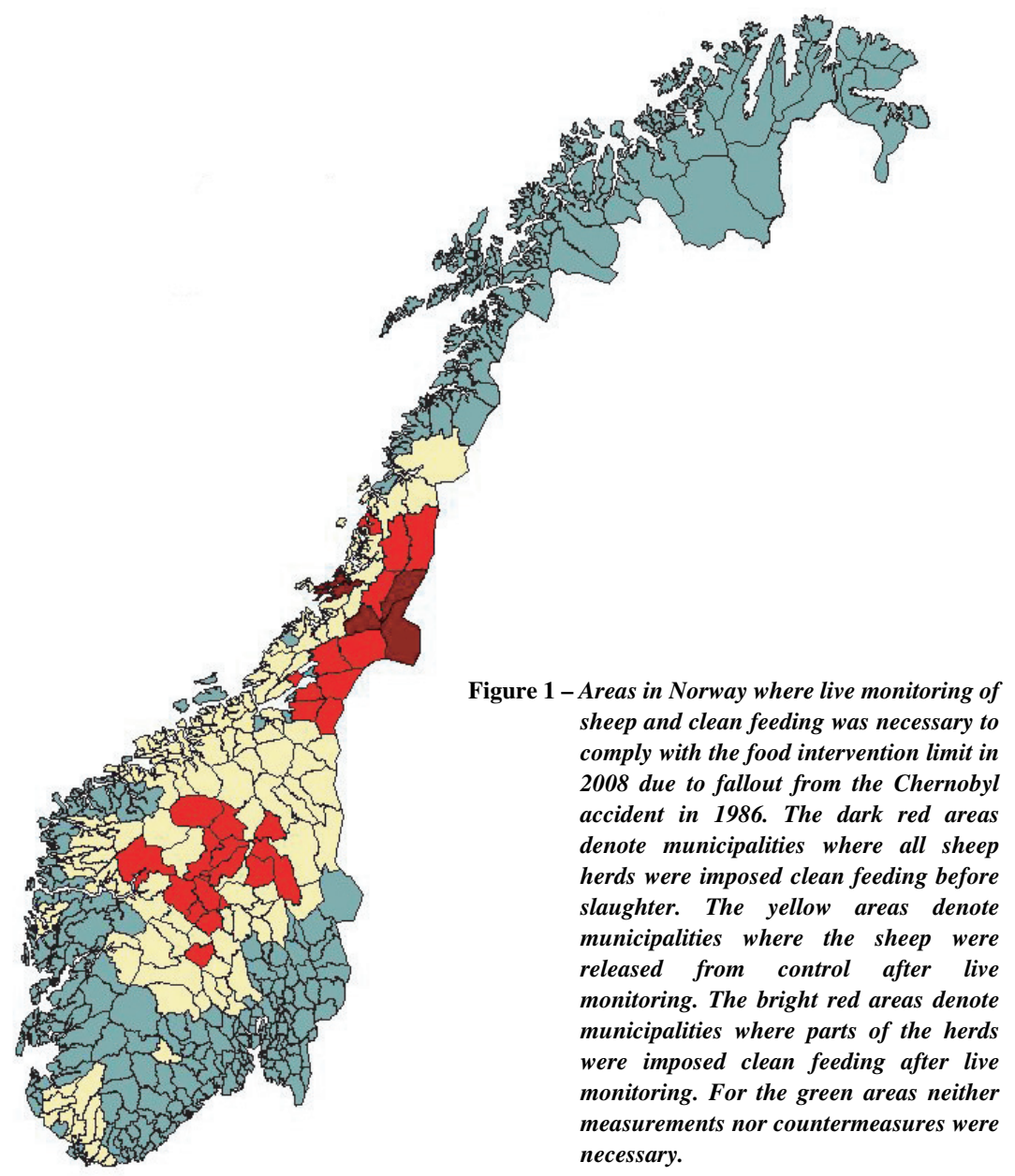

The use of countermeasures in agriculture and reindeer husbandry has become part of normal practice in many areas in Norway. Figure 1 shows the areas where live monitoring and clean feeding was still in use in 2008. It is envisaged that countermeasures will be needed for at least another decade to produce food that comply with the food intervention limits 6 .

\footnotetext{
6 These levels are today $600 \mathrm{~Bq} / \mathrm{kg}$ for basic foodstuffs, $370 \mathrm{~Bq} / \mathrm{kg}$ for milk and infants' food and $3000 \mathrm{~Bq} / \mathrm{kg}$ for reindeer, game and wild freshwater fish.
} 
Part of the development process of the EURANOS Framework for the elaboration of post-accident rehabilitation preparedness strategies (Dubreuil et al., 2010) involved both a French and a Norwegian Pilot Study who profited from visits to the contaminated regions of Norway where experience from living in and managing a contaminated area was shared between national and regional authorities, local administration, health care personnel, and local farmers and reindeer herders. Within the EURANOS project, procedures were tested for increased dialogue between the various national, regional and local actors; extended stakeholder engagement in decision making processes; and increased awareness by all participants as to the shared responsibility of stakeholders. This method was termed the IDPA ${ }^{7}$ method, first applied in the French Pilot Study (EURANOS, 2009), where four successive stages are discussed:

O identification of the issues at stake, of the involved entities and actors, of the strategic core of the problem;

○ diagnosis of engaged actions;

o prospective forecasting: evolution of the situation, the problem and the solutions; and

○ action proposals.

This procedure is characterised by an increased participation of local actors and lay-persons, compared to standard stakeholder engagement procedures (like expert advisory boards). It also contributes to an increased awareness of the shared responsibility of the various actors for finding sound and generally acceptable solutions.

Two reports summarising procedures and main findings were published after the two seminars (see Oughton et al., 2008; Bay-Larsen et al., 2009), from which this paper is deducted.

\section{The Norwegian pilot study}

\subsection{Method}

Two stakeholder meetings were arranged in spring 2008 as part of the Norwegian Pilot Study, the first in Steinkjer, a region still affected by the Chernobyl contamination, and the second in Oslo. Approximately 25 people participated in each meeting; the majority of participants were present in both meetings. They were representatives of local communities, agriculture, reindeer herding, fisheries, industry, outdoor groups and national and regional authorities. The Norwegian

\footnotetext{
7 IDPA: Identification, Diagnosis, Prospective, Action proposals.
} 
Radiation Protection Authority (NRPA) was responsible for arranging the seminars and presentations, while two independent facilitators from the Norwegian University of Life Sciences and the Nordland Research Institute were running the discussions and reporting the results. This ensured that the participants' views and recommendations were reported independently and also enabled NRPA to participate in this co-expertise process at an equal level as the other participants.

The methodology used was based on the IDPA method tested by the French stakeholders. The first seminar introduced the group to the theme of rehabilitation of areas that faces long-term management, and to the IDPA methodology. The first meeting was dedicated to the identification (I) stage of the method, while DPA where addressed at the second meeting five weeks later. The aim of the seminars was to give concrete recommendations for authorities and decision-makers on the strengthening of Norwegian preparedness for rehabilitation.

During the seminars short introductory presentations were given on relevant topics, by stakeholders taking part in the seminar and by other invited speakers. Then discussions took place in plenary and in smaller break-out groups, designed to encompass a large variety of actors and sectors for the benefit of co-expertise discussions. They were run by independent facilitators, while the groups chose a chairperson and a secretary themselves and reported their summaries in plenary. The facilitators summarised the discussions and recommendations in reports that were distributed to the participants for comments and revision.

\subsection{The Steinkjer seminar}

Representatives from various stakeholder groups attended the seminar: local farmers, health care personnel and reindeer herders; local, regional and national authorities within food safety, environmental protection and radiation protection; industry and nature groups. The purpose of the seminar was to identify the key challenges - as seen by each of the participants - related to long-term management and rehabilitation of radioactively contaminated areas. Some participants had experience in dealing with the Chernobyl consequences while others were new to the topic. All participants, however, had views and/or experience from other accidents/emergency situations that proved useful also for the objectives of this seminar. The discussions thus reflected both on the experience from the past and possible solutions/improvements in today's society.

The following topics were identified by the participants as the most important ones for a thorough discussion at the following Oslo seminar:

○ organisation of emergency preparedness at a local level; 
○ psychosocial effects;

o information needs and strategies;

o possible challenges for other socio-economic sectors besides agriculture and reindeer breeding.

In addition, a specific case study was chosen, namely the possible lowering of the food intervention level for reindeer meat from $3000 \mathrm{~Bq} / \mathrm{kg}$ to 1500 or even $600 \mathrm{~Bq} / \mathrm{kg}$.

\subsection{The Oslo seminar}

In addition to participants from the Steinkjer seminar, more representatives from national authorities (in particular the health sector) and other economic sectors attended the meeting in Oslo. Each of the chosen topics above was introduced by one or two short presentations to set the scene. Then the topics were further discussed in-depth in smaller break-out groups, following the same procedure as in Steinkjer. The participants were encouraged to come up with concrete recommendations for the Norwegian Nuclear and Radiological Emergency Organisation.

The participants were active and enthusiastic and a number of interesting challenges and solutions were discussed for each topic. The summary of proposals to deal with the challenges for each topic is given below.

\subsubsection{Organisation of emergency preparedness at a local level}

The municipalities need local advisors in order to deal with a long-term contamination situation since few employees are dealing with emergency preparedness in general in the local administrations on a daily basis. People in local hospitals, environmental laboratories, voluntary organisations or other people outside the general preparedness organisation were identified as possible resources for important additional support for handling the situation. The local administration should make plans for how to cooperate with local resources in case of a contamination incident/accident.

The number of local food control stations has significantly decreased the latest years due to a national reorganisation of the food administration sector from 2004. This change led to the closure of former local food safety laboratories, of which only some were transformed into private or inter-municipality laboratories. Due to a limited demand for analyses of radioactivity in foodstuffs, several private labs decided to close down the radiation measurement service. This decrease in measurement capacity is of great concern to people in the districts. The Food 
Safety Authority should increase their local engagement and investigate how the situation could be improved at the local level.

Finally, the central authorities (in particular health and food safety) should contribute actively to the implementation of sector policies at the regional and local level in cooperation with the County Governor.

\subsubsection{Psychosocial effects and information needs}

The discussion on psychosocial effects was largely tied to the discussions on information needs and strategies, since poor information is assumed to contribute considerably to psychosocial stress in the population. Several suggestions for improvements were made. Firstly, the health sector should be included in the rehabilitation work, particularly at the local level. Secondly, there is a need to sum up existing documentation on health-effects on humans and animals following long-term radioactive contamination, including psychosocial effects and personal experience. Further, it was suggested that the competence and experience from dealing with the Chernobyl accident should be summarized and used to develop guidance for post-accident rehabilitation in the future. Finally, the Sami population group, who has been offered whole body measurements since the Chernobyl accident, expressed a need for a more thorough health follow-up programme. Only monitoring of the internal contamination of ${ }^{137} \mathrm{Cs}$ is not seen as sufficient to address their concerns about their personal health and that of their family.

\subsubsection{Other economic and non-commercial sectors}

Possible consequences for tourism and outdoor activities were addressed. The number of foreign tourists to Norway has increased substantially the last 20 years. A major part of the tourism is based on the attraction of the undisturbed nature. Little information is known about the consequences of the Chernobyl fallout on tourism and outdoor activities in the early years after the accident. Given a new accident, however, the tourist industry will probably be affected more strongly and more directly today than in 1986. It is unsure whether this industry has any contingency plans for such an event.

As for outdoor activities, it was a general view that there would be a high demand for analysis of environmental samples, freshwater fish, game, berries and mushrooms, since $80 \%$ of Norwegians are engaged in various kinds of outdoor activities on a regular basis (according to the Directorate of nature management). The decrease in local monitoring stations is again a concern, since there will be a need for surveys of the local situation to give public guidance on safe areas and foodstuffs from the wild. 
Another important sector is the sea food export industry. Although the marine environment is less vulnerable to radioactive contamination than terrestrial or freshwater environments, the export industry is very vulnerable to rumours or suspicion of radioactive contamination of sea food. Experience has shown that costumers would easily stop all import of possibly contaminated sea food. A radiation accident that impacts the marine environment could thus entail substantial consequences for society and economy besides radiation issues. It is important to clarify responsibilities and roles in advance between the industries and the authorities in case of a contamination situation.

\subsubsection{Lowering the food intervention limit for reindeer meat}

The possible lowering of the food intervention level for reindeer meat from $3000 \mathrm{~Bq} / \mathrm{kg}$ to 1500 or even $600 \mathrm{~Bq} / \mathrm{kg}$ was chosen as a specific case-study. The reason for this topic was an assignment from the Ministry of Health and Care Services to the NRPA and the Food Safety Authority to assess the possibilities, consequences and justification for lowering the food intervention limit to comply with the level for basic foodstuffs. It is worth noting that this limit was raised from $600 \mathrm{~Bq} / \mathrm{kg}$ to $6000 \mathrm{~Bq} / \mathrm{kg}$ in 1986 to be able to preserve reindeer herding as a primary industry, an industry that risked total eradication due to the radioactive fallout. The limit was lowered to $3000 \mathrm{~Bq} / \mathrm{kg}$ in 1994 when the contamination and countermeasures reached a level where a decrease was both feasible and costefficient.

This topic caused a lot of debate and it was emphasised that reindeer herding is not only an economic industry, but an important culture bearer for the Sami population. If reindeer herding was to be discontinued due to new restricting rules, the Sami culture and language would suffer. The financial compensation given to herders today for performing countermeasures, are not sufficient to cover the actual extra expenses of the actions taken. A lowering of the food intervention limit would drastically increase the need for countermeasures and entail lots of extra work and resources. Reindeer herders, radiation protection specialists and the Food Safety Authority all agreed that most probably the positive effects of a reduced food intervention level would not outweigh the negative impacts. It is also important to remember that reindeers are not only used for meat supply; they are also important as raw material for crafts and traditional cooking.

\section{Overall summary and recommendations from the seminars}

The participants agreed on a list of recommendations that they would forward to the Norwegian Nuclear and Radiological Emergency Organisation. These are summarised below. 
1) At the local level, nuclear emergency preparedness should be strengthened with the aid of:

a. local measurement stations;

b. municipality emergency plans;

c. involvement of the primary health services.

2) At the State level, nuclear emergency preparedness should be strengthened with the aid of:

a. sector-wide implementation of countermeasures on a regional and local level;

b. improved follow-up of the municipalities.

3) There is a particular need for both the Food Safety Authority and the health sectors to clarify their roles in emergency preparedness.

4) The present knowledge and competence needs to be maintained and developed in the form of:

a. documentation and transfer of experience from Chernobyl;

b. improving the knowledge on radiation issues in the general public;

c. dissemination of the conclusions of research and studies.

5) Information strategies are an important means of alleviating psycho-social stress in the public. Information must be consistent, based on local measurements (in affected areas) and be available in more languages than Norwegian and Sami in today's multilingual society.

6) Any eventual reduction in the food intervention level for radioactive caesium in reindeer meat needs to be evaluated with respect to social, health, cultural and economic factors. At the present time, the benefits of such a reduction appear to be small compared to the disadvantages.

7) The roles and division of responsibilities between industry and authorities should be clarified with respect to risks to market and image perception and measurement capacity.

A full summary of the Norwegian Pilot study is available in Norwegian (BayLarsen et al., 2009) and in English (Oughton et al., 2008).

\section{Summary and experience from the pilot study approach}

Norway has many reasons for strengthening its co-expertise management of nuclear/radiological emergencies. Firstly, the present Norwegian Nuclear Emergency Response Organisation is primarily "top-down" driven, challenging the adaptation to local, hands-on experiences and needs. Hence, a robust system for engagement of local authorities and stakeholders has yet to be developed. For instance, the role of local doctors and health centres has been ignored so far. Secondly, changes in society such as privatisation of the Food Safety Authority's 
laboratories and closing of local Agriculture Inspection Service's offices, present challenges for any new emergency. Moreover, possibilities for local-national interaction have changed dramatically during the last 20 years with the introduction of new communication tools like internet and cell phones. Today, a wide range of options for local stakeholder involvement and dialogue exist, both in an emergency situation and in evaluating and developing new policies. Finally, although Norway has important experience from post-Chernobyl management, this knowledge is fading. Hence there is a need to share experience between regions affected by Chernobyl and those not affected.

The Pilot Study described shows a clear potential for improving the Norwegian emergency preparedness and response. An adapted IDPA method was used and found to be useful for facilitating the discussions/process. It is important that sufficient time is given to the discussion phase so that all participants have time to reflect and present their views. Independent facilitation ensures that the summary of the discussions are not biased. The main benefits of the technique are clearly the multidisciplinary aspects and that actors with a wide range of experience and expertise are brought together. While it has not been possible to test against other procedures, hence there may be alternative methods that can also foster co-operation at this level, it is clear that this type of stakeholder dialogue gives valuable input when developing future preparedness plans, particularly for extending the engagement of local and lay actors. In particular, the Norwegian participants stressed the following aspects when giving feedback on the participatory design on the seminars. First, they acknowledged the need for participation and to share experience. Secondly, they emphasised the need for communicating objectives for participation, so that feedback is targeted. Thirdly, by arranging two seminars, their perception of issues at stake was allowed to mature over time. Finally, the group size should not exceed 10-12 persons to have a fruitful dialogue.

It should also be noted that even though the aim of the seminar was to reflect on long-term management, the discussions also covered the immediate emergency phase. When discussing the consequences, recovery and rehabilitation from a nuclear/radiological accident, it is natural to cover the whole time span from preparedness to recovery and rehabilitation as the actions chosen in the early phase would influence on the late phase response. However, it is important to emphasise the possible long duration of the contamination problem as management and rehabilitation action may be necessary for years or even decades.

The original aims and success criteria of the Pilot Study were as follows:

- to have a group balanced between national, regional and local actors;

- to have a group able to review lessons from the past and to make recommendations; 
- the participants are ready to be an asset in case of future contamination;

- an increase of awareness on this issue; and

- a better understanding of the responsibilities of each stakeholder (national, regional and local).

Measured against these criteria, it is obvious that the Pilot Study has fulfilled its original intentions. Even though there were some negative remarks concerning repetition and relevance of issues, the overwhelming response from participants was positive, particularly from local actors who felt that their opinions and knowledge had not previously been taken into account by national authorities. However, at the end of the day, the success of this pilot study will be measured by the extent to which the participants' recommendations will be taken seriously by the Norwegian emergency preparedness authorities and realised in their procedures and future activities.

\section{REFERENCES}

Bay-Larsen I., Oughton D., Liland A., Eikelmann I.M., Hansen H.S. (2009) Experience-based knowledge in nuclear and radiological emergency preparedness - involvement of national stakeholders. Report from the EURANOS project. StrålevernRapport 2009:8. Østerås: Norwegian Radiation Protection Authority.

Dubreuil G.H., Baudé S., Lochard J., Ollagnon H., Liland A. (2010) The EURANOS cooperative framework for preparedness and management strategies of the long-term consequences of a radiological event, Radioprotection 45, S199-S213.

EURANOS (2009) Sustainable rehabilitation of living conditions in contaminated territories after a nuclear accident or a radiological event - Revised framework for the elaboration of postaccident rehabilitation preparedness strategies. Deliverable Report for the EURANOS project. European Commission.

Liland A., Lochard J., Skuterud L. (2009) How long is long-term? Reflections based on over 20 years of post-Chernobyl management in Norway, J. Environ. Radioact. 100, 581-584.

Oughton D., Liland A., Bay I., Eikelmann I.M., Solheim-Hansen H., Skuterud L.. (2008) Long-term rehabilitation of Contaminated Areas in Norway: outcomes of co-expertise meetings. Deliverable report D8C3R1 for the European Commission. 